\title{
A NIRS-Aided Methodology to Elucidate the Nutrition of the Endangered Mountain Gazelle (Gazella gazella) Using Samples of Rumen Contents from Roadkills
}

\author{
Amir Arnon ${ }^{1,2, *(D)}$, Serge Yan Landau ${ }^{3}$, Ido Izhaki ${ }^{1}$ (D), Dan Malkinson ${ }^{4}$, Yaniv Levy-Paz ${ }^{2}$ \\ Tova Deutch-Traubman ${ }^{3}$, Hillary Voet ${ }^{5}$, Ori Segev ${ }^{6}$ and Guy Dovrat ${ }^{6}$
}

check for updates

Citation: Arnon, A.; Landau, S.Y.; Izhaki, I.; Malkinson, D.; Levy-Paz, Y.; Deutch-Traubman, T.; Voet, H.; Segev, O.; Dovrat, G. A NIRS-Aided Methodology to Elucidate the Nutrition of the Endangered Mountain Gazelle (Gazella gazella) Using Samples of Rumen Contents from Roadkills. Remote Sens. 2021, 13, 4279. https://doi.org/10.3390/ rs13214279

Academic Editors: Doug Tolleson and Carrie Vance

Received: 2 August 2021

Accepted: 20 October 2021

Published: 24 October 2021

Publisher's Note: MDPI stays neutral with regard to jurisdictional claims in published maps and institutional affiliations.

Copyright: (c) 2021 by the authors. Licensee MDPI, Basel, Switzerland. This article is an open access article distributed under the terms and conditions of the Creative Commons Attribution (CC BY) license (https:// creativecommons.org/licenses/by/ $4.0 /)$.
1 Department of Evolution and Environmental Biology, University of Haifa, Haifa 3498838, Israel; izhaki@research.haifa.ac.il

2 Ganei Ramat Hanadiv P.O.B 325, Zikhron Ya'akov 3095202, Israel; Yaniv@ramathanadiv.org.il

3 Department of Natural Resources, Agricultural Research Organization-The Volcani Center, Bet Dagan 50250, Israel; vclandau@volcani.agri.gov.il (S.Y.L.); tovad@volcani.agri.gov.il (T.D.-T.)

4 Department of Geography and Environmental Studies, University of Haifa, Haifa 3498838, Israel; dmalk@geo.haifa.ac.il

5 Robert H. Smith Faculty of Agriculture, Food and Environment Department of Environmental Economics and Management, Hebrew University, Rehovot 76100, Israel; hillary.voet@mail.huji.ac.il

6 Department of Natural Resources, Newe Ya'ar Research Center, Agricultural Research Organization-The Volcani Center, P.O. Box 1021, Ramat Yishay 30095, Israel; orisgv@gmail.com (O.S.);

dovrat@volcani.agri.gov.il (G.D.)

* Correspondence: amir@ramathanadiv.org.il

Abstract: The populations of the endangered mountain gazelle (Gazella gazella), which inhabit large parts of Israel, across various ecosystems and climatic conditions, shrunk drastically over the last decades. To date, data on gazelle nutrition, how these relate with individual characteristics and respond to seasonal and environmental changes, have not been available. We analyzed 110 samples from gazelle rumen contents collected throughout the country from occasional fatalities, mainly roadkills, and tested the feasibility of using them for near-infrared spectrometry (NIRS) calibrations. Although NIR calibrations for crude protein, in vitro dry matter digestibility, and ash were reasonable, we found that using calibrations based on local forage and feed plant species performed better, and used these to estimate several nutritional constituents in gazelle rumens, using NIRS. We tested how constituents relate to the sex, age-class, and weight of the individual gazelle, and to season and ecosystem type, and found that season plays a major role in gazelle nutrition. Winter is the most propitious season, when crude protein, ash and digestibility are highest, and acid detergent fiber $(\mathrm{ADF})$, neutral detergent fiber (NDF), and the carbon to nitrogen (C:N) ratio are lowest. Autumn, being the harshest season, mirrors winter conditions, and summer and spring show intermediate levels. Yet the relative changes between seasons were mild: about $30 \%$, for crude protein, digestibility, and ash, and $14-22 \%$ for ADF, NDF, and C:N ratio. Ecosystem type affected several constituents, and nutrition was slightly better in Mediterranean than in dry ecosystems. Gazelle sex, weight, and age-class had minor effects on nutrition. Overall, it seems that the adaptation of gazelles to their environment is germane to keeping relatively steady nutrition throughout the year. Our results, which do not show a dramatic decline in the quality of gazelle nutrition during any season or among the climatic regions that were studied, suggest that nutrition is not a major driver of the survival of gazelles in the populations surveyed.

Keywords: Gazella gazella; ruminant nutrition; wildlife nutrition; NIRS; rumen content

\section{Introduction}

The mountain gazelle (Gazella gazella) is a key species in Israel's fauna, from the ecological, conservation, and public points of view. It occupies many ecosystems throughout large 
parts of the country, and under diverse climatic conditions from desert plains, through garrigue and shrubland to natural and planted forests, and from semi-arid to mountainous forested climatic zones [1]. In these habitats, gazelles serve as an important prey, grazer, and sometimes an agricultural pest [1]. G. gazella status is endangered (EN) [2], with an estimated population size of 5000 [3]. This is the last viable remnant of the species, which once roamed vast parts of the Levant [4]. Studies on mountain gazelles in Israel $[5,6]$ found that gazelles adapt their diet to forage availability and palatability, moving from mostly grazing in winter and spring to mostly browsing in summer and autumn. However, these studies covered only a handful of habitats in northern Israel, and have not assessed the nutritional value of the diets consumed, and how it varies between seasons and ecosystems. Furthermore, although the current status of G. gazella is still relatively fair, no study to date has evaluated whether the nutrition of gazelles at certain regions or along specific seasons, deteriorates to such low levels which could impair gazelle survival, which might explain declines in some populations.

Nutrition affects key aspects in wildlife biology, including survival and reproduction rates. Knowledge of a species' nutritional habits, requirements and status is, therefore, highly relevant to its management and conservation [7-9]. A better understanding of a species nutritional status in different habitats and seasons could aid management and conservation decisions, which could range between choosing preferred habitats and/or seasons for reintroducing animals to the wild [10], to extreme measures such as providing supplementary food and water [11]. A few constituents are typically used to characterize key attributes of ungulate nutrition. Dietary nitrogen $(\mathrm{N})$ is commonly used to evaluate the diet of ruminants, both wild [10,12,13], and domesticated [14-16]. Nitrogen content is usually positively correlated with digestibility, rumen bacterial activity, and digestive tract turnover $[17,18]$, and negatively with the content of fiber attributes, such as NDF and ADF [19]. The carbon to nitrogen $(\mathrm{C}: \mathrm{N})$ ratio is another important index for forage quality [20], with higher ratios correlating with increases in structural carbohydrate content and reductions in $\mathrm{N}$ content.

Assessing the nutrition of wild ungulates can be both time-consuming and expensive [21]. Furthermore, because the diet of a species may vary between seasons [22,23] and habitats $[9,24]$, the relevance of any knowledge gained could be highly site and timespecific. To alleviate this, fecal indices for dietary constituents are used extensively to follow spatiotemporal changes and trends in dietary constituents [25], as sampling of feces provides an accessible, noninvasive tool that can be used for studying large areas and over long periods. However, without calibrations built using constituent data from the actual diet consumed by a herbivore, fecal indices may only serve for relative comparisons [21]. Moreover, the value and reliability of these indices in predicting nutritional status are questionable. Fecal nitrogen (FN), for example, has long been used as an indicator of nutritional status [26], and has been instrumental in monitoring nutrition in wild ungulates, under a wide array of climates; e.g., white-tailed deer (Odocoileus virginianus) in Canada [27], Mongolian gazelles (Procapra gutturosa) in Mongolia [28], bighorn sheep (Ovis canadensis) in the US [29], and sable antelope (Hippotragus niger) in South Africa [13]. Fecal N is highly correlated to dietary crude protein (CP) [30], responsive to seasonal variation in grass quality [14], and can be used to predict organic matter digestibility [26,31], although this relationship holds better for temperate than tropical forages [32]. However, the use of FN is controversial and is advised only with comparable study units, i.e., ecosystems with similar forage characteristics such as composition of woody and herbaceous species, and within a species [21], mainly because it is affected by dietary tannins that bind with proteins along the gastrointestinal tract, hence, increasing their percentage in feces [33]. Another obstacle is the efficiency of urea cycling in the rumen by desert-dwelling animals as shown for several species, e.g. the Nubian Ibex (Capra nubiana) [34], which limits the amount of $\mathrm{N}$ that reaches the feces.

Another limitation of using data from fecal samples is that typically there is no information on the individual being sampled, such as sex, age, and weight. As intraspecific 
dietary differences may be considerable, e.g., sexual dimorphism associated with different nutritional demands [35], such lack of data might constrain inference or lead to erroneous conclusions.

To overcome these limitations, various studies used samples obtained from the rumen of hunted ungulates, right after the animal was shot, e.g., [36-38]. More recently, Djordjevic [22] analyzed rumen contents of 20 roe deer (Capreolus capreolus) and studied seasonal dietary differences, to support informed planning of the composition of winter supplementary feeds, and König et al. [23] collected samples every month along three years, from a total of 245 shot roe deer, and compared the quality of diets between individuals residing in agricultural or natural habitats. Redjadj et al. [39] sampled approximately 100 rumens of four wild ungulate species. They assessed the diet composition and quality of each species and used these data to run a comprehensive analysis on several topics, including temporal changes in diets, and differences between species.

As demonstrated by the aforementioned studies, game species are readily available for sampling rumen content. Although the availability of hunted animals may be restricted to specific seasons, sexes, and/or age-classes, samples collected this way are very fresh and can be rapidly frozen for further analyses. Naturally, this is not the case with protected species, as demonstrated by the work of Spalton [40], who evaluated the dietary status of the critically endangered Arabian oryx (Oryx leucoryx) based on estimates of digestibility, protein, and water in rumen contents of 10 individuals which died during a drought.

In this study, we extended the use of ungulate carcasses as a source for rumen samples, to the endangered mountain gazelle, using available carcasses, mostly roadkills, to study variation in nutrition among individuals and sexes, between seasons, and across ecosystems. To facilitate the chemical analyses of samples we incorporated near-infrared spectrometry (NIRS), which is based on the unique reflectance and absorbance in the NIR wavelengths (750-2500 $\mathrm{nm}$ ) of different organic compounds [41,42]. NIRS involves much less labor, processing time, and chemicals than standard lab procedures [43], and requires low inputs, except for the purchase of a NIR scanner [44]. NIRS requires calibrations for the specific substances through paired reflectance spectra and chemical measurements from numerous samples, but the availability of gazelle carcasses is limited. This can be overcome because a major advantage of the NIRS methodology is the generation of big databases including spectral data from a wide array of biological samples: for instance, our spectral library includes thousands of feeds from Mediterranean to hyper-arid environments and multi-species feces, encompassing cattle, goats, and wildlife $[10,14,16]$. Taking into account rigorous statistical constraints, NIRS calibrations can be re-calculated after spectra are tapped from the library to complete a database where the number of collected samples is too small. Due to these advantages, using NIRS facilitates the procession of large numbers of samples, and enable conducting studies at large spatial and temporal scales.

As done previously in our study with Arabian Oryx [10], here, we capitalize on the findings of Purnomoadi et al. [45] who used NIR spectra of feeds and feces as one spectral population found in a continuum in the gastrointestinal tract, and applied this principle to rumen contents.

Specifically we (a) compared the performance of two sets of calibrations-one is based on data from carcasses and the second on a large, existing dataset of forage and feeds, and (b) examined the effects of individual characteristics, body mass, sex and age-class, and environmental conditions-ecosystem type and season, on gazelle nutrition.

\section{Materials and Methods}

\subsection{Collecting Gazelle Carcasses}

Rangers of the Israeli Nature and Parks Authority (INPA) routinely encounter dead or injured gazelles, either during patrols or following reports by drivers, hikers, etc. Dead gazelles are usually transferred to regional freezers and stored at $-20^{\circ} \mathrm{C}$ until collected by the National Zoological Collections at the Steinhardt Museum of Natural History, while injured ones are immediately transported to the Wildlife Hospital, a cooperation of the 
INPA and the Safari Zoological Center at Ramat Gan, Israel. Gazelles that recuperate are released back to nature.

We contacted the INPA, Wildlife Hospital, and National Zoological Collections, and asked to be notified when dead gazelles were collected. For each gazelle reported, we recorded available data on the death and collection circumstances, including location, time and cause of death, and the time between injury to death, and between death and freezing (if the carcass was frozen). A few rumen samples were collected by veterinarians who performed necropsies. All samples were collected under INPA permits.

Between 1 May 2108 and 31 December 2020 we collected 110 mountain gazelle carcasses. Most gazelles (77\%) were hit by cars, while the rest died due to disease, predation, and poaching. Sample distribution according to year and month of death is described in Table 1. Thirty-three gazelles were collected from dry and 73 from Mediterranean regions (below and above $400 \mathrm{~mm}$ rain $*$ year $^{-1}$, respectively). Forty-five gazelles were females, 60 were males, five unknown. Eighty were adults, 25 young, five unknown.

Table 1. The number of gazelle carcasses (samples) collected along the study period, by months and years. For three carcasses out of the total 110 collected, we did not have records of month, year, or both.

\begin{tabular}{ccccc}
\hline Month & $\mathbf{2 0 1 8}$ & $\mathbf{2 0 1 9}$ & $\mathbf{2 0 2 0}$ & Total \\
\hline January & - & 3 & 4 & 7 \\
\hline February & - & 3 & 2 & 5 \\
\hline March & - & 4 & 4 & 5 \\
\hline April & 3 & 5 & 2 & 12 \\
\hline May & 6 & 11 & - & 8 \\
\hline June & 1 & 7 & 3 & 8 \\
\hline July & 3 & 2 & 1 & 8 \\
\hline August & 2 & 5 & 4 & 3 \\
\hline September & 2 & - & 7 & 15 \\
\hline October & 1 & 3 & 1 & 9 \\
\hline November & 2 & 6 & 30 & 107 \\
\hline December & 2 & 6 & & 8 \\
\hline Total & 22 & 55 & & 19 \\
\hline
\end{tabular}

Average individual weights by sex and age-class are presented in Table 2 .

Table 2. Mean gazelle body weight, in $\mathrm{kg}( \pm \mathrm{SD})$, and the number of carcasses collected, by sex and age-class; for five individuals, weight records were missing.

\begin{tabular}{cccc}
\hline Category & Male & Female & All \\
\hline Young & $15.40 \pm 3.67 ; n=13$ & $12.27 \pm 2.72 ; n=12$ & $13.96 \pm 3.58 ; n=25$ \\
\hline Adult & $22.38 \pm 2.63 ; n=47$ & $17.26 \pm 2.55 ; n=33$ & $20.38 \pm 3.79 ; n=80$ \\
\hline All & $20.90 \pm 4.39 ; n=60$ & $15.89 \pm 3.41 ; n=45$ & $18.70 \pm 4.70 ; n=105$ \\
\hline
\end{tabular}

\subsection{Sampling, Preparation, and Chemical Analyses of Rumen Contents}

Frozen gazelles were thawed at room temperature until they became soft enough for processing, with time duration typically ranging between approximately 8 to 36 hours, depending on the season. We sampled rumen content by first removing the rumen, and then cutting an incision in its wall, mixing the content, and collecting a fistful, approximately 25 grams. Five rumen contents were too small to be analyzed. For each sample, we 
documented conspicuous attributes such as bad smell, macerated content, slimy texture, etc., and assigned a quality score to it, on a 1-10 scale, according to its state, with 10 representing a fresh sample from a full rumen. After drying the rumen contents at $55^{\circ} \mathrm{C}$ for 96 hours, we manually removed large, hard pits, mostly of olives (Olea europaea), Christ's thorn jujube (Ziziphus spinachristi), and carobs (Ceratonia siliqua), which are typically spat out by gazelles during regurgitation, either while standing or at bedding sites [1] (see Figures 1 and 2). All samples were ground to pass a 1-mm sieve (Cyclotec 1093 Sample Mill, Foss Tecator, Höganas, Sweden).

We used wet chemistry analyses to measure seven nutritional constituents. Assays included the contents in dry matter of $\mathrm{CP}$, using an automated Kjeldahl method according to procedure 976.05 of AOAC [46]; NDF, after $\alpha$-amylase and inclusive of residual ash, and ADF, inclusive of residual ash, by standard methods: Ankom; according to Goering and Van Soest [47]; in vitro dry matter digestibility (IVDMD) according to Tilley and Terry [48], and ash (after combustion at $550{ }^{\circ} \mathrm{C}$ for four hours). We also measured $\mathrm{C}$ and $\mathrm{N}$ contents using an Elemental Analyzer (FLASH2000 CN, Thermo Scientific, Waltham, MA, USA).

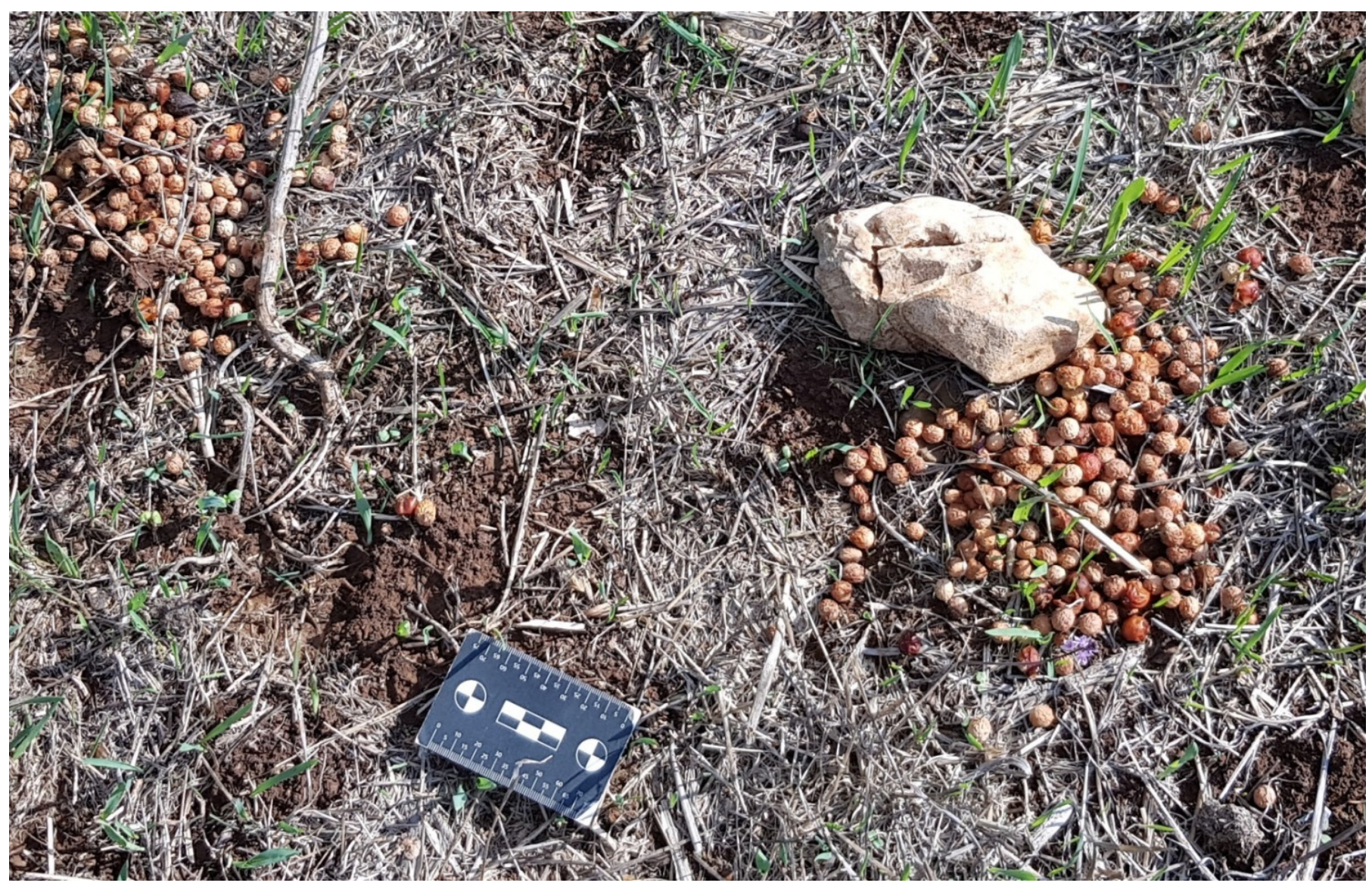

Figure 1. Indigestible fruit pits spat out by gazelles during resting and regurgitating while standing up. Such pits were removed from rumen contents before analyses. Photo by A.A. 

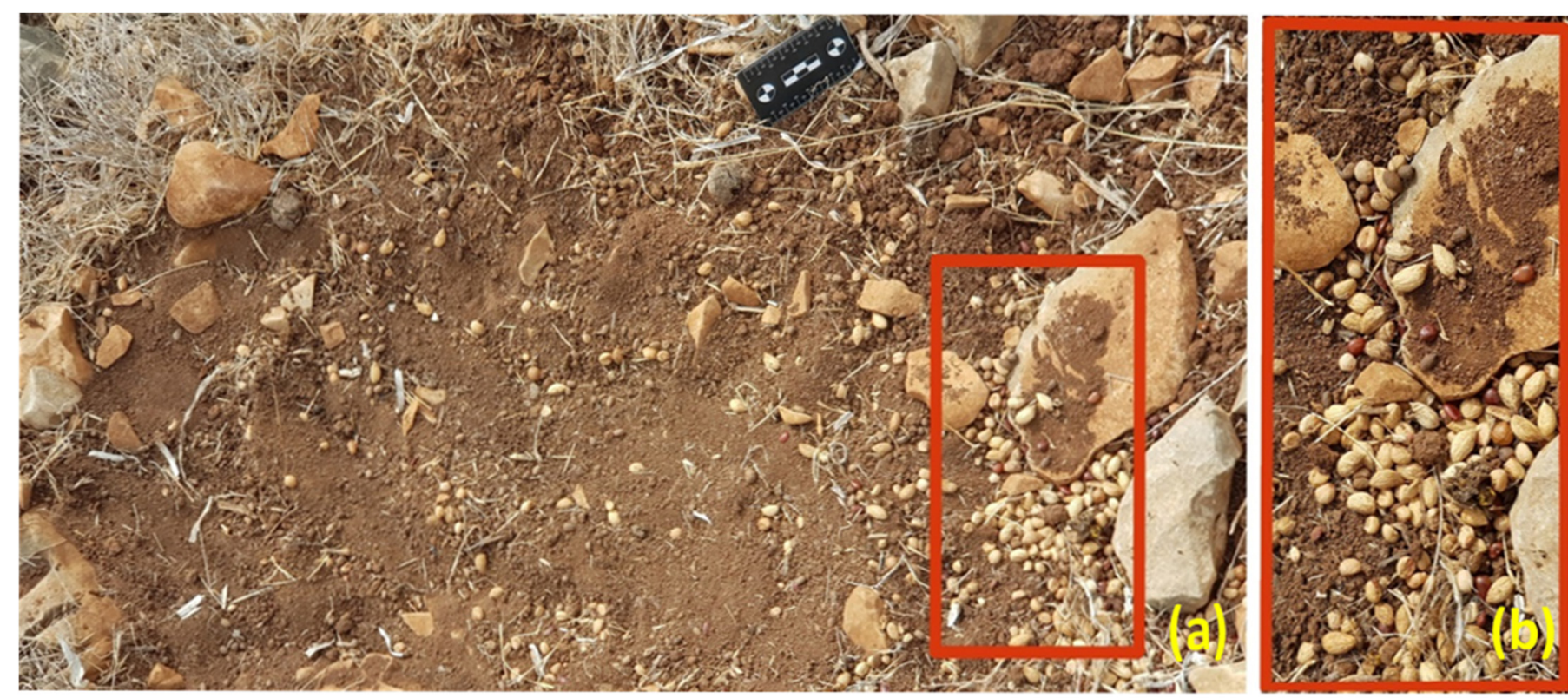

Figure 2. Indigestible fruit pits spat out by gazelles while lying down at a bedding site. (a) Pits (mostly of olives, but also of carobs and other fruits) are dispersed all over the bedding site. A large concentrations can be seen on the right hand side, enlarged in (b). Such pits were removed from rumen contents before analyses. Photo by A.A.

Crude protein in rumen contents is higher than in the ruminant diet because it also includes microbial protein [49]. In an attempt to separate microbial materials from food, we first tested the possibility of water rinsing the rumen contents, following Nocek's protocol [50]. However, the outcome of rinsing varied between constituents; $\mathrm{CP}$ was not correlated between rumen contents before and after washing $(\mathrm{r}=0.085, n=91, p=0.45)$, whereas stronger but still weak correlations were found for $\operatorname{ADF}(\mathrm{r}=0.24, n=91, p=0.032)$, $\mathrm{NDF}(\mathrm{r}=0.28, n=91, p=0.014)$, IVDMD $(\mathrm{r}=0.51, \mathrm{n}=34, p<0.0001)$, and ash $(\mathrm{r}=0.35$, $n=91, p=0.0015)$.

In order to avoid biases and be consistent, we therefore used only the unwashed samples in the statistical models, as representing all the constituents of gazelle nutrition. Washed samples were still included in the NIRS calibration procedures only, to widen spectral diversity.

\subsection{Near-Infrared (NIR) Scans}

Rumen samples were re-dried at $50{ }^{\circ} \mathrm{C}$ for one hour and put into a desiccator for $20 \mathrm{~min}$ before being packed into sample cells with a near-infrared transparent quartz cover glass. Samples were scanned in $2 \mathrm{~nm}$ increments between 1100 and $2498 \mathrm{~nm}$, using a Foss NIR Systems model 5000 monochromator spectrometer (Foss Tecator, Hoganas, Sweden). Spectra, presented in Figure 3, were collected as $\log (1 / R)$, where $R=$ reflectance. Raw spectral data were transformed with the standard normal variate (SNV) and detrending procedures to remove non-linearity that results from light scattering [51]. Mathematical treatments used to enhance spectral differences where " $1,4,4,1$ " or " $2,6,6,2$ ", where the numbers represent: the derivative; gap width over which the derivative is calculated; the number of points in a moving average, i.e., first smoothing procedure; and the number of nm over which the second smoothing is applied, respectively [52]. 


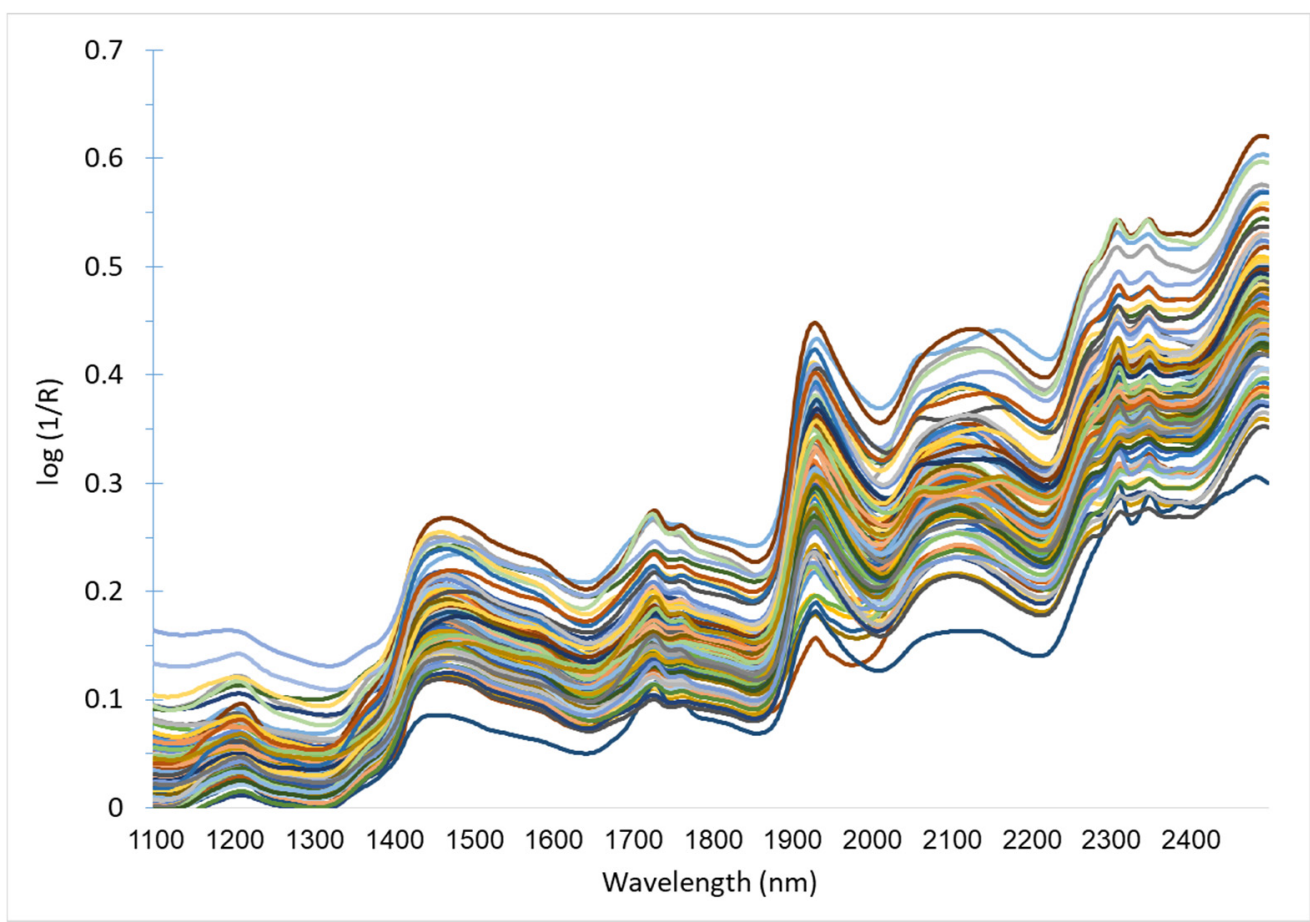

Figure 3. Untransformed near-infrared (NIR) spectra of rumen contents, sampled from gazelle carcasses $(n=100)$.

\subsection{Calibrating NIR Spectra to Reference Values}

In addition to constructing calibrations for the different constituents, based on chemical analyses of the rumen contents that we sampled, we tested the possibility of utilizing existing databases of vegetation (forage and feeds), which we acquired throughout many previous studies on the nutrition of ruminants in the region $[10,14,16,44,53]$. The spectral analyses thus incorporated two datasets (Table 3), one obtained from dead gazelles, hereafter, carcasses, and a second comprising multiple samples, which were NIR-scanned and assessed with wet chemistry, of various natural and cultivated plant species, which are consumed by both wild and domestic ungulates, hereafter, feeds. To ensure that samples from both datasets belong to the same statistical population, we calculated the standardized $\mathrm{H}$ of each carcass sample to the spectral centroid of the feed samples and applied NIRS equations only to samples with H lower than three standard deviations (SD) [54].

Table 3. Description of the two datasets used for NIRS-aided prediction of various constituents in gazelle rumen contents: crude protein (CP), neutral detergent fiber (NDF), acid detergent fiber (ADF), in vitro dry matter digestibility (IVDMD), Carbon (C), Nitrogen (N), and polyethylene glycol-binding tannins (PEG-b-t). The number of samples used for calibrating each constituent in parentheses.

\begin{tabular}{ccc}
\hline Dataset & Sample Type & Constituents Predicted by the Dataset \\
\hline Carcasses & Rumen contents & $\begin{array}{c}\text { CP (96), NDF (96), ADF (96), ash (96), } \\
\text { IVDMD (36), C (80), N (80), C:N (80) }\end{array}$ \\
\hline \multirow{2}{*}{ Feeds } & $\begin{array}{r}\text { Food items: herbaceous and woody } \\
\text { forage plants, both cultivated and wild }\end{array}$ & CP (619), NDF (619), ADF (619), ash (511), \\
& IVDMD (292), PEG-b-t (116) \\
\hline
\end{tabular}

We used the modified partial least-squares (mPLS) routine, which is commonly applied in NIRS to develop calibration equations from the treated spectral data. Partial least-squares (PLS) regression models are based on principal components of both the independent data $X$ and the dependent data $Y$. The central idea is to calculate the principal component scores of the $\mathrm{X}$ and the $\mathrm{Y}$ data matrix and to set up a regression model between the scores (and not the original data). The important point when setting up a PLS model is 
to make a decision for the optimal number of principal components involved in the PLS model. While this can be done from variation criteria for other models, for PLS the optimal number of components has to be determined empirically by cross validation of the PLS model using an increasing number of components. Modified partial least-squares divides the calibration set into a number of subsets, and performs cross-validation to establish the number of PLS factors and to reduce the possibility of overfitting [55].

The performance of the different calibrations was evaluated using different estimates of quality: coefficient of determination $\left(\mathrm{R}^{2} \mathrm{cal}\right)$ defines the proportion of variability in the reference data, accounted for by the regression equation, encompassing both linearity and precision; the standard error of calibration (SEC), the variability in the differences between predicted and reference values; the average root mean square difference between predicted and reference (observed) values calculated for the results of cross-validation (SECV); and the coefficient of determination in cross-validations $\left(\mathrm{R}^{2} \mathrm{CV}\right)$. Cross-validation may yield over-optimistic results, especially if data are replicated, but is justified in situations where the calibration samples are randomly selected from a natural population [56]. Another measure of performance for NIRS calibrations is the ratio of performance to deviation (RPD), calculated as the ratio of SD to SECV, with 2.5 considered the lowest acceptable value $[25,57]$.

\subsection{Predicting Rumen Constituents with NIRS}

After we obtained calibration equations based on the carcasses dataset, we used them to predict the constituents calibrated for all rumen contents. We also used the calibrations which were based on the feeds dataset, to predict CP, NDF, ADF, ash, IVDMD, and content of polyethylene glycol-binding tannins (PEG-b-t) in rumen contents. Additionally, we validated the feeds-based predictions for constituents in rumen contents (CP, NDF, ADF, ash, IVDMD), by regressing these on the wet chemistry measurements, i.e., a complete separation between the calibration and validation datasets, and testing whether the slopes and intercepts of the linear fit between them differed significantly from 1 and 0 , respectively.

All NIRS calibrations, analyses, and predictions were calculated with WinISI 2 software $\mathrm{V} 1.02$ [52].

\subsection{Statistical Analyses}

To follow changes in gazelle nutrition, we built a separate statistical model for each constituent for which we obtained a satisfactory calibration, i.e. adequate linearity (precision) coefficient $\left(R^{2}\right.$ cal $\left.\geq 0.90\right)$, and a high enough accuracy ( $\left.R P D \geq 2.5\right)$ [57]. Factors considered as explanatory variables were sex, weight, age-class: adult or young (above or below one year, respectively), ecosystem type: dry or Mediterranean (below and above 400 $\mathrm{mm}$ rain $*$ year $^{-1}$, respectively), season: autumn (Oct., Nov., Dec.); winter (Jan., Feb., Mar.); spring (Apr., May, June); summer (July, Aug., Sep.), and year. Data were examined for outliers based on standardized residuals from the predicted means using all these factors, and values whose absolute standardized residual was three or greater were eliminated. We then ran separate ANOVA analyses for each constituent with all factors included, screened for significance using a criterion of $p<0.10$, and ran a second analysis with only the factors retained. We ran the selected models separately, with and without weighting samples by their quality score, to test how the physical condition of the rumen contents affects the statistical models. Post-hoc comparisons were performed by the Tukey test. Statistical significance was set at alpha $=0.05$. Statistical analyses were undertaken using JMP (15.0)

\section{Results}

\subsection{NIRS Calibrations}

The mean $\mathrm{H}$ of rumen samples from the spectral centroid of the feeds dataset was $1.20 \pm 0.75 \mathrm{SD}$, i.e., very close to the spectral centroid of the feeds database, and only three rumen samples had $\mathrm{H}>3$ SD. Therefore, we concluded that using the feed-based NIRS calibrations was justifiable, as supported by the external chemical validation (Figure 4). 
Table 4 specifies the performance of the calibrations by each of the two datasets, for the various dietary constituents. For all constituents for which we had NIRS calibrations from both carcass and feeds datasets, the performance of calibrations with feeds was better. Calibrations for $\mathrm{C}$ and $\mathrm{N}$ in rumen contents performed very well, under all criteria. Nonetheless, the C:N ratio was predicted with less precision and accuracy than $\mathrm{C}$ and $\mathrm{N}$ separately. Also, the error of prediction was higher than its theoretical value, i.e., the sum of those for $\mathrm{C}$ and $\mathrm{N}$. Therefore, we derived the $\mathrm{C}: \mathrm{N}$ ratio from the $\mathrm{C}$ and $\mathrm{N}$ values determined separately.

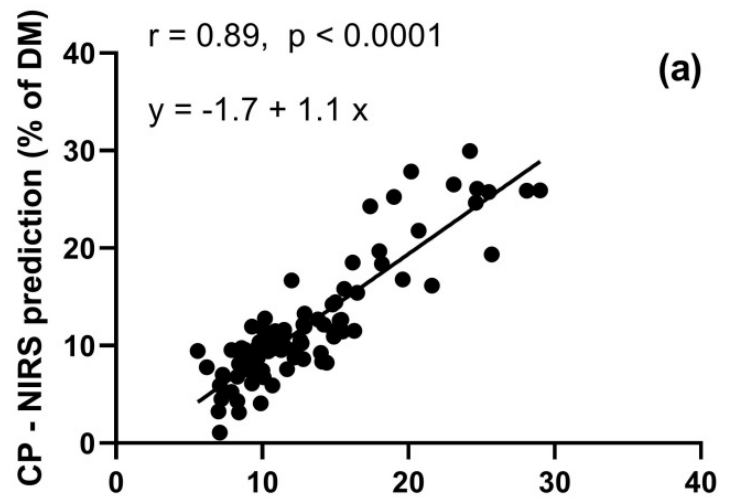

CP - Wet chemistry measurement (\% of DM)

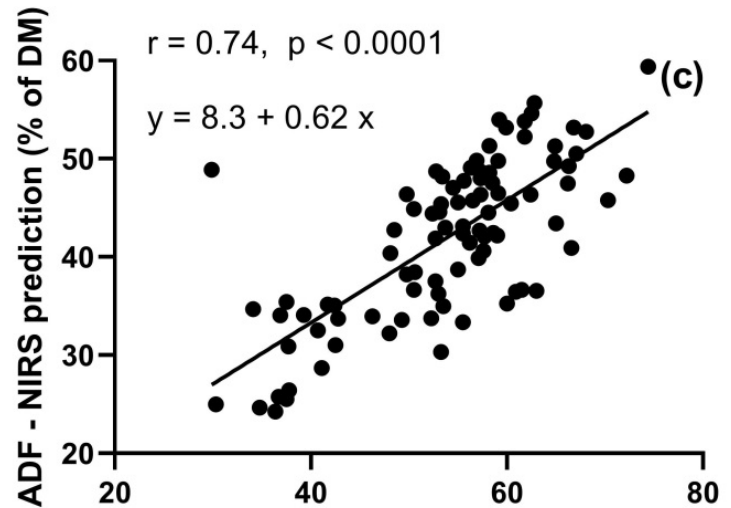

ADF - Wet chemistry measurement (\% of DM)
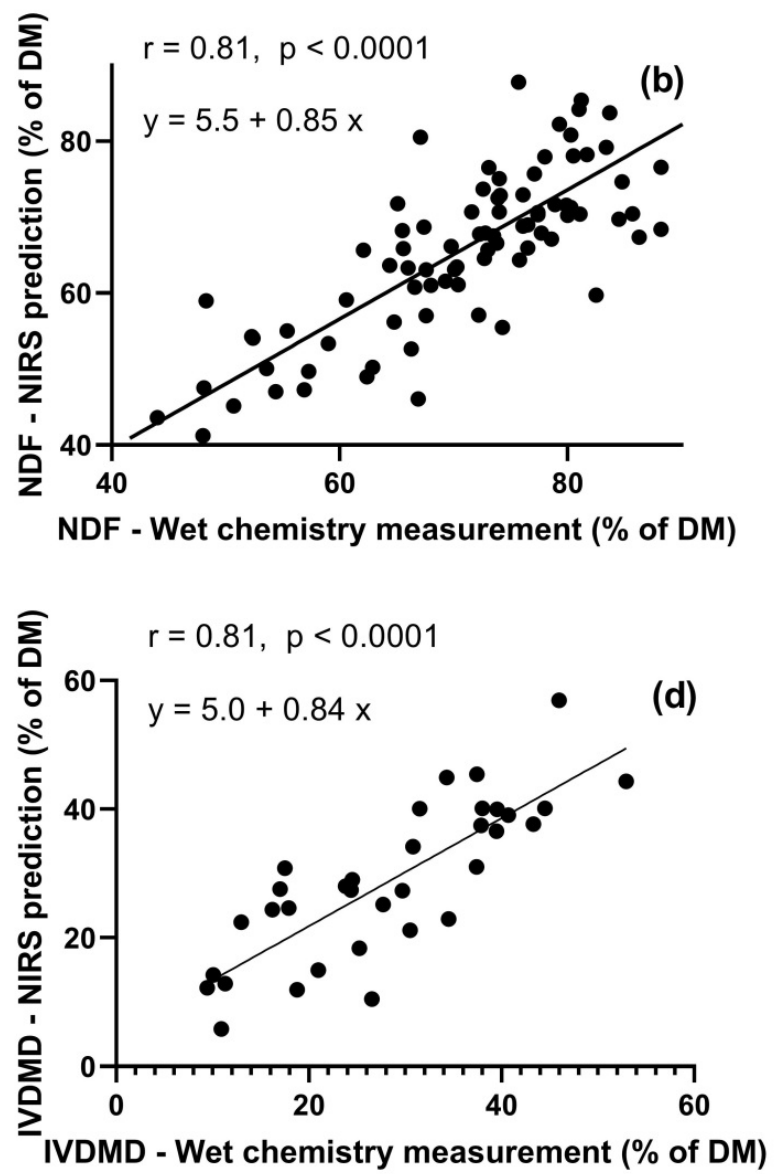

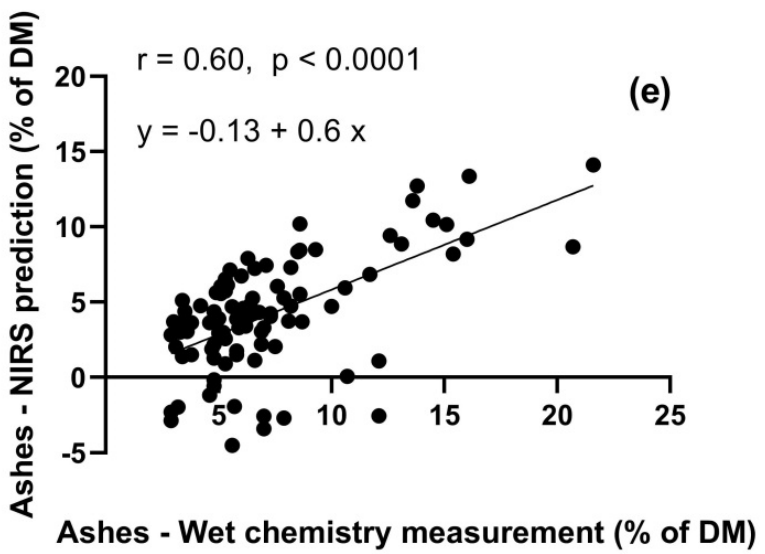

Figure 4. External validation of near-infrared spectrometry (NIRS) predictions with chemical measurements, of several nutritional constituents in gazelle rumen contents: CP (a), NDF (b), ADF (c), IVDMD (d), and ash (e). NIRS predictions were based on calibrations which used rangeland herbage and browse forage species (the Feeds dataset). 
Table 4. Near-infrared spectrometry calibration performance, for the prediction of the chemical composition of gazelle rumen contents, including the number of samples used for each calibration (n), the mean and the standard deviation (SD) of measurements, standard errors of calibration (SEC) and cross-validation (SECV), calibration ( $\mathrm{R}^{2}$ cal) and cross-validation $\left(R^{2} \mathrm{cv}\right)$ coefficients, the ratio of performance to deviation (RPD), and derivatives used in mathematical treatment (DER, 1st or 2 nd). In bold, the calibrations selected for the analysis of rumen contents from 105 gazelles in the survey.

\begin{tabular}{|c|c|c|c|c|c|c|c|c|c|c|}
\hline Calibration Dataset & Constituent & $n$ & Mean & SD & SEC & $\mathbf{R}^{2}$ cal & SECV & $R^{2} \mathrm{cv}$ & RPD & DER \\
\hline \multirow{8}{*}{ Carcasses } & Crude protein & 88 & 11.97 & 4.15 & 0.78 & 0.96 & 1.22 & 0.91 & 3.39 & 1 \\
\hline & ADF & 93 & 53.67 & 9.26 & 3.64 & 0.85 & 4.55 & 0.76 & 2.04 & 2 \\
\hline & NDF & 94 & 70.92 & 10.59 & 3.43 & 0.89 & 4.89 & 0.8 & 2.16 & 1 \\
\hline & IVDMD & 28 & 30.00 & 12.0 & 4.0 & 0.92 & 5.00 & 0.86 & 2.69 & 1 \\
\hline & Ash & 92 & 6.87 & 3.48 & 1.2 & 0.88 & 1.33 & 0.85 & 2.62 & 1 \\
\hline & $\mathrm{C}$ & 67 & 45.74 & 2.42 & 0.62 & 0.93 & 0.81 & 0.89 & 3 & 1 \\
\hline & $\mathrm{N}$ & 70 & 2.85 & 1.01 & 0.2 & 0.96 & 0.28 & 0.92 & 3.64 & 2 \\
\hline & C:N & 69 & 18.28 & 6.81 & 1.98 & 0.92 & 2.72 & 0.84 & 2.5 & 1 \\
\hline \multirow{6}{*}{ Feeds } & Crude protein & 584 & 11.93 & 5.18 & 0.92 & 0.97 & 1 & 0.96 & 5.18 & 1 \\
\hline & ADF & 584 & 29.29 & 7.44 & 2.4 & 0.9 & 2.6 & 0.88 & 2.87 & 1 \\
\hline & NDF & 586 & 45.43 & 12.31 & 3.38 & 0.92 & 3.69 & 0.91 & 3.34 & 1 \\
\hline & IVDMD & 280 & 55.16 & 17.45 & 3.25 & 0.97 & 3.64 & 0.96 & 4.8 & 1 \\
\hline & Ash & 477 & 7.93 & 3.25 & 0.96 & 0.91 & 1.08 & 0.89 & 3 & 2 \\
\hline & PEG-b-t & 111 & 6.55 & 5.59 & 1 & 0.97 & 1.29 & 0.95 & 4.35 & 1 \\
\hline
\end{tabular}

For CP, NDF, ADF, IVDMD, ash (\% of DM), the external validation (Figure 4) yielded slopes of $1.05,0.85,0.62,0.82$, and 0.60 ; and intercepts of $-1.68,5.46,8.31,0.06$, and -0.13 ., respectively. Given the $95 \%$ confidence interval, the slopes and intercepts of $\mathrm{CP}, \mathrm{NDF}, \mathrm{ADF}$, and IVDMD did not differ from 1 and 0 , respectively, or were very close to them. Pearson correlation coefficients were satisfactory for $\mathrm{CP}(\mathrm{r}=0.89)$, NDF $(\mathrm{r}=0.81)$, and IVDMD $(r=0.81)$, but not for ADF and ash $(r=0.74$ and $r=0.6$, respectively).

\subsection{Gazelle Nutrition-Changes in Constituents, and the Factors Affecting Them}

While most constituents were significantly affected by one to three factors out of season, ecosystem type, sex, and age-class, there were no interactions between these factors (Table 5). Accordingly, results for each constituent are presented by each of the factors which were found to significantly affect it. The results (Figure 5) show that NDF content in the rumen was highest in autumn $(54.1 \%)$, intermediate in spring $(50.9 \%)$ and summer $(49.8 \%)$, and lowest in winter $(46.7 \%)$. NDF levels were higher for gazelles residing in dry (52.1\%) than in Mediterranean areas (48.7\%). ADF exhibited similar seasonal patterns, although the significant differences are between winter $(27.2 \%)$ and the other seasons: autumn $(35.1 \%)$, spring $(33.7 \%)$, and summer $(32.4 \%)$. ADF did not change significantly between dry and Mediterranean ecosystems. Similar to NDF and ADF, C:N ratio was highest in autumn $(15.0 \%)$, decreased in winter $(12.5 \%)$ and spring $(13.0 \%)$, and increased again through summer (13.1\%). C:N ratio was slightly lower in the diet of adult $(12.7 \%)$ than young $(14.0 \%)$ gazelles. Although these C:N trends are statistically significant, the differences are quite small. In vitro dry matter digestibility showed the opposite trends from NDF (and to a lesser extent, ADF), both between seasons, and ecosystems. It peaked in winter $(47.3 \%)$, and was lowest in autumn $(36.32 \%)$, with intermediate levels in spring $(43.6 \%)$ and summer $(44.6 \%)$, and was slightly though significantly, lower in dry $(41.0 \%)$ than in Mediterranean ecosystems (44.9\%). Crude protein (CP) showed similar changes between seasons as IVDMD, with the highest levels in winter (24.6\%), decreasing through spring $(22.0 \%)$ and summer $(21.3 \%)$ to $18.2 \%$ in autumn. Unlike IVDMD, CP did not change significantly between ecosystems. Ash content was highest in winter (10.5\%) and intermediate in spring $(8.7 \%)$, summer $(8.9 \%)$ and autumn $(9.0 \%)$. It was higher in Mediterranean $(9.8 \%)$ than in dry $(8.7 \%)$ ecosystems, and in the diet of adult $(9.8 \%)$ than 
of young $(8.7 \%)$ gazelles. Finally, tannins (PEG-b-t), at an average level of $2.2 \%$, did not change significantly between seasons, ecosystem types or age class.

Season Ecosystem type Age class

ADF

C:N

IVDMD

Crude

Protein

Ash

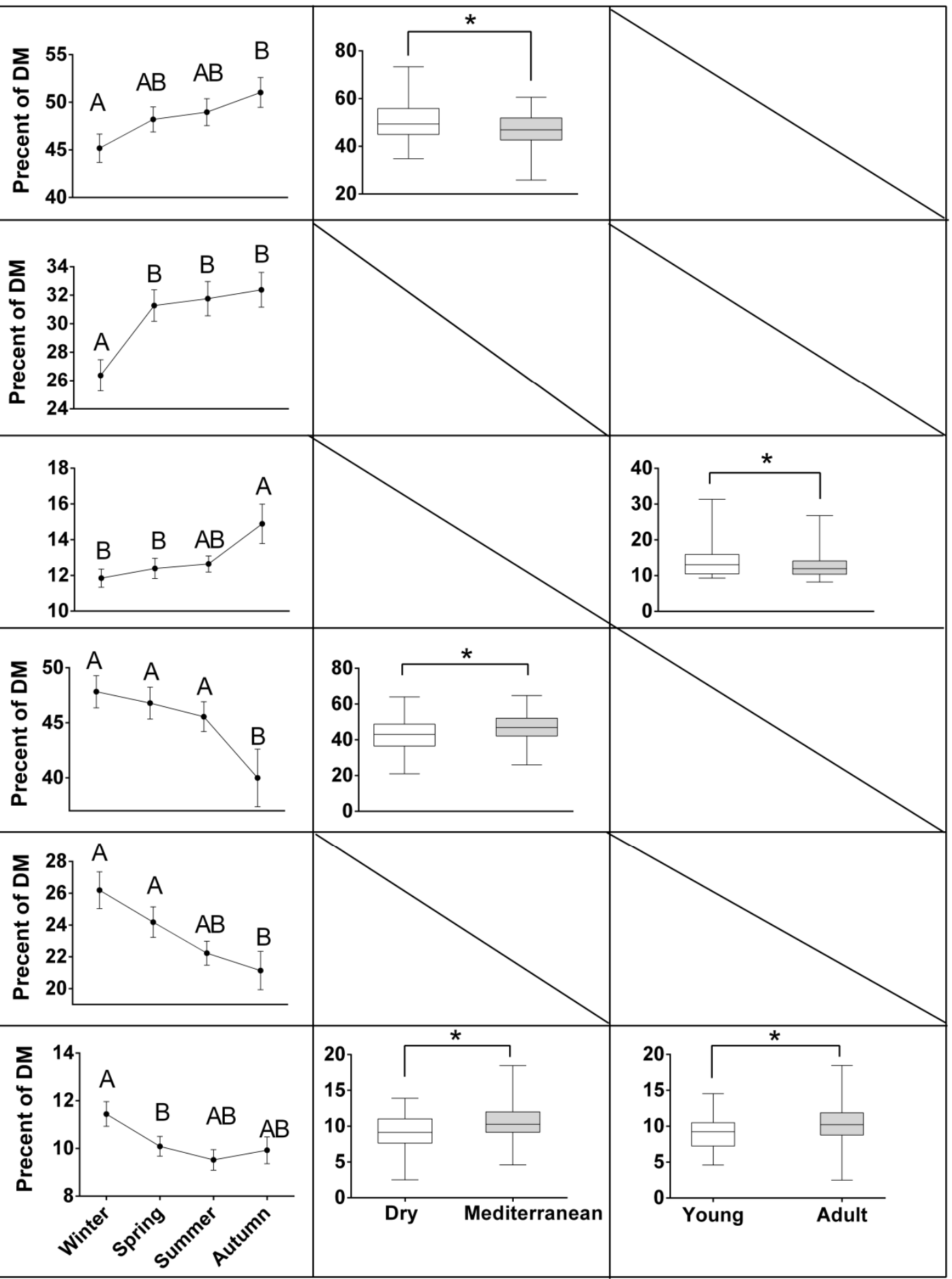

Figure 5. Contents of nutritional constituents (percent of dry matter; DM, except for C:N ratio) in mountain gazelle rumens, estimated with near-infrared spectrometry (NIRS). Means ( \pm standard error) are presented for seasons, significantly different if not connected by the same letters (Tukey's post- hoc; $p<0.05$ ). Boxplots depict the median and interquartile range, by ecosystem type and age class, with significantly different levels connected by * $(p<0.05)$. Numerical results are presented in Tables 5 and 6. 
Table 5. Main details of two-way ANOVA tests for nutritional constituents in samples from mountain gazelle rumens, predicted by near-infrared spectrometry.

\begin{tabular}{|c|c|c|c|c|c|c|c|c|}
\hline Constituent & Variable & Season & Ecosystem & Season $x$ Ecosystem & Age-Class & Sex & Mean Square & df \\
\hline \multirow{2}{*}{ Protein } & F Statistic & 5.69 & 2.94 & 0.34 & & 3.35 & \multirow{2}{*}{105.68} & \multirow{2}{*}{87} \\
\hline & $p$-value & 0.0013 & 0.090 & 0.79 & & 0.071 & & \\
\hline \multirow{2}{*}{$\mathrm{ADF}$} & F Statistic & 7.3105 & 2.7957 & 0.7422 & & & \multirow{2}{*}{140.57} & \multirow{2}{*}{88} \\
\hline & $p$-value & 0.0002 & 0.098 & 0.53 & & & & \\
\hline \multirow{2}{*}{ NDF } & F Statistic & 4.18 & 5.37 & 0.35 & & & \multirow{2}{*}{196.17} & \multirow{2}{*}{87} \\
\hline & $p$-value & 0.0081 & 0.0228 & 0.79 & & & & \\
\hline \multirow{2}{*}{ IVDMD } & F Statistic & 6.65 & 4.83 & 0.25 & & & \multirow{2}{*}{296.96} & \multirow{2}{*}{88} \\
\hline & $p$-value & 0.0004 & 0.0305 & 0.86 & & & & \\
\hline \multirow{2}{*}{ Ash } & F Statistic & 3.32 & 5.99 & 0.81 & 6.20 & & \multirow{2}{*}{19.38} & \multirow{2}{*}{87} \\
\hline & $p$-value & 0.0234 & 0.0164 & 0.49 & 0.0147 & & & \\
\hline \multirow{2}{*}{$\mathrm{C}: \mathrm{N}$} & F Statistic & 3.40 & & & 4.15 & & \multirow{2}{*}{33.89} & \multirow{2}{*}{89} \\
\hline & $p$-value & 0.0211 & & & 0.0447 & & & \\
\hline \multirow{2}{*}{ PEG-b-t } & F Statistic & 0.44 & 0.43 & 0.31 & & & \multirow{2}{*}{26.11} & \multirow{2}{*}{88} \\
\hline & $p$-value & 0.72 & 0.51 & 0.82 & & & & \\
\hline
\end{tabular}

Table 6. Means \pm standard errors (SE) of the different nutritional constituents, as predicted using NIRS, according to season (Aut., Win., Spr., Sum., for autumn, winter, spring, and summer, respectively), ecosystem type (Dry, and Med. for Mediterranean), age-class (Adu., You., for adult and young, respectively), and sex (Fem., Mal., for female and male, respectively). Values may differ slightly from Figure 5, as the table presents raw means.

\begin{tabular}{|c|c|c|c|c|c|c|c|c|c|c|c|}
\hline \multirow[b]{2}{*}{ Constituent } & \multirow[b]{2}{*}{ Level } & \multicolumn{4}{|c|}{ Season } & \multicolumn{2}{|c|}{ Ecosystem Type } & \multicolumn{2}{|c|}{ Age Class } & \multicolumn{2}{|c|}{ Sex } \\
\hline & & Win. & Spr. & Sum. & Aut. & Dry & Med. & Adu. & You. & Fem. & Mal. \\
\hline \multirow{2}{*}{ NDF } & Mean & 46.4 & 49.3 & 49.2 & 53.7 & 52.1 & 48.8 & 48.0 & 50.9 & 48.7 & 48.2 \\
\hline & SE & 1.8 & 1.46 & 1.63 & 1.68 & 1.18 & 0.81 & 0.84 & 1.33 & 1.01 & 1.04 \\
\hline \multirow{2}{*}{$\mathrm{ADF}$} & Mean & 27.2 & 32.4 & 32.1 & 34.7 & 32.3 & 29.7 & 30.3 & 32.4 & 30.8 & 32.3 \\
\hline & SE & 1.32 & 1.07 & 1.19 & 1.23 & 1.13 & 0.71 & 0.73 & 0.99 & 0.87 & 0.86 \\
\hline \multirow{2}{*}{$\mathrm{C}: \mathrm{N}$} & Mean & 12.1 & 12.6 & 12.8 & 14.8 & 13.3 & 12.5 & 12.6 & 14.1 & 12.9 & 12.9 \\
\hline & SE & 0.65 & 0.47 & 0.57 & 0.59 & 0.68 & 0.41 & 0.33 & 0.52 & 0.44 & 0.52 \\
\hline \multirow{2}{*}{ IVDMD } & Mean & 47.6 & 45.4 & 45.0 & 37.0 & 41.0 & 45.0 & 45.9 & 42.4 & 44.9 & 45.6 \\
\hline & SE & 1.92 & 1.56 & 1.73 & 1.79 & 1.44 & 1.0 & 0.73 & 0.99 & 1.12 & 1.19 \\
\hline \multirow{2}{*}{ Crude protein } & Mean & 24.9 & 22.9 & 21.7 & 18.9 & 20.8 & 22.4 & 23.8 & 21.6 & 21.4 & 22.6 \\
\hline & SE & 1.15 & 0.93 & 1.06 & 1.08 & 0.99 & 0.69 & 0.56 & 1.2 & 0.79 & 0.65 \\
\hline \multirow{2}{*}{ Ashes } & Mean & 11.01 & 9.6 & 9.2 & 9.1 & 8.9 & 10.0 & 10.0 & 8.7 & 10.2 & 10.2 \\
\hline & SE & 0.51 & 0.42 & 0.45 & 0.46 & 0.38 & 0.27 & 0.26 & 0.39 & 0.34 & 0.35 \\
\hline \multirow{2}{*}{ PEG-b-t } & Mean & 2.13 & 2.54 & 2.12 & 2.0 & 2.46 & 2.12 & 2.21 & 2.07 & 2.12 & 2.14 \\
\hline & SE & 0.57 & 0.46 & 0.51 & 0.53 & 0.43 & 0.3 & 0.27 & 0.44 & 0.34 & 0.31 \\
\hline
\end{tabular}

We present results only for the tests which included weighting of samples by their quality scores-an assessment of the sample quality-although this only slightly improved the overall performance of statistical models, as reflected in slightly higher $\mathrm{R}^{2}$ values (an average increase of 0.021 ). Weighting samples by their quality score had a minor effect also on the significance of factors. 


\section{Discussion}

\subsection{Using NIRS to Estimate Chemical Constituents in Rumen Contents}

While the NIRS calibrations which were based on gazelle rumen contents performed quite well, we estimated they could be improved by increasing the number of calibrated samples and widening spectral variation. However, the number of roadkills was not high enough to provide additional samples during the study period. Therefore, we took a different approach: we estimated that spectrally, samples from rumens may be considered as part of the database of ungulate feeds - natural and cultivated plant species from the research region, which are consumed by the ruminants being studied, and thus constitute their rumen content. We validated this approach with an external validation of NIRS predictions using wet chemistry measurements, and obtained satisfying results for $\mathrm{CP}$, NDF and IVDMD, which, combined together, provide insights into gazelle nutrition and the factors affecting it. The existence of large calibration databases from different locations could thus facilitate the prediction of constituents in herbivore gut contents, and as our findings showed, could certainly be instrumental in the investigation of the nutrition of endangered species. A similar approach was used by Redjadj et al. [39], who hypothesized that a combined calibration could be performed for 118 samples from different wild ruminants and 900 samples of feeds from the French CIRAD database, because the groups appeared to overlap in chemical composition and spectral profiles. The resulting calibration equations had a $0.96 \mathrm{R}^{2}$ and standard error of $0.15 \%$ for $\mathrm{CP}$ content, 0.94 and $3.40 \%$ for NDF, 0.95 and $2.50 \%$ for ADF, which is similar to our results (Table 4). However, these authors did not present an external validation.

\subsection{Rumen Contents as Proxies for Nutrition}

Once the methodological questions concerned with calibrations and analyses are solved, the major question remains: can rumen content be used as proxies for nutrition? We will discuss $\mathrm{CP}$ as it is a paramount factor in nutrition. Values for $\mathrm{CP}$ in gazelle ruminal contents fluctuate between $18 \%$ to $25 \%$, on a DM basis, which are high in comparison to dietary $\mathrm{CP}$ for other free-ranging ruminants. For example, in Mediterranean ecosystems, dietary $\mathrm{CP}$ for cattle in herbaceous pastures range between $8 \%$ of DM ingested in summer, to more than $20 \%$ in winter lush green herbage $[14,16]$; and for ranging goats in woodland, between $9-10 \%$ in summer and $13-15 \%$ of DM in winter [58,59]. In other words, CP seems to be higher in the rumen than in herbage or browse, a discrepancy which was not considered in previous studies, which discussed rumen contents as though they directly represent nutrition, e.g. $[23,39]$. The higher $\mathrm{CP}$ in the rumen could be attributed to microbial protein, which is highly affected by dietary protein and urea recycling [50]. A notable exception is the rumen contents of Oryx, which had similar CP content as local grass, but the animals sampled literally starved to death-they were sampled during a drought [40]. Comparing cattle and deer, [50] concluded that urea-recycling was species-dependent. There is evidence that desert animals have superior N-recycling ability via saliva, as shown in Nubian Ibex [34], dik-dik antelopes (Rhynchotragus kirkii) [60], and Bedouin Sinai goats [61], thus buffering the low nitrogen content in the feed.

\subsection{Using Roadkill to Study Ungulate Nutrition}

Dead wildlife, especially roadkills, can provide valuable nutritional and dietary information, for both basic and conservation-oriented research. Hence, these sad deaths can be used to enhance the conservation of remaining populations. Diet is an additional area in which data gathered by roadkill surveys can facilitate ecological studies, i.e., monitoring population trends; mapping of species distribution; studying animal behavior, and monitoring of contaminants and disease [62]. Unlike the Oryx sampled by Spalton [40], which died during a drought, road-killed animals are usually healthy individuals, which can serve as 'sentinels' for environmental and wildlife health [62]. However, since some diseases may cause animals to be more susceptible to being hit by vehicles [63], it is advised to assess the physical state of the individual sampled, to avoid biases associated with sick 
individuals. Once good calibrations of spectra and constituents are obtained, studies that utilize the methodology presented here could gain considerably by conducting NIRS scans on-site, with a lightweight portable instrument, as demonstrated for feces by [64]. This will facilitate the logistics involved with such an intensive effort, and more importantly, improve the quality of samples, as the time of transportation, freezing and de-freezing is saved.

It is important to note that the time between the death of the animal and rumen sampling or freezing varied between individuals. While food intake stops with an animal's death or injury, the activity of bacteria and protozoa continues, which could potentially lead to biases in the estimates of substances in the rumen. This might explain why, in contrast with CP, IVDMD was much lower in rumen contents than in feeds. Along digestion, highly digestible components (cell contents, soluble carbohydrates, cellulose) disappear from the rumen rapidly, leaving room for components of low digestibility [49]. Therefore, any interpolation from ruminal attributes to diet and nutrition must be very cautious. The relationship between the state of rumen content and its representability needs further research. However, the inner consistency of our results, such as expected seasonal trends and negative and positive relationships between different constituents, together with the fact that including sample scores_-an assessment of the overall quality of the sample had only minor effects on the statistical models-supports the validity of using roadkills as a source for rumen samples.

\subsection{The Nutrition of Mountain Gazelles}

Broadly speaking, the constituents which we examined can be divided into two categories: NDF, $\mathrm{ADF}$, and tannin contents, and $\mathrm{C}: \mathrm{N}$ ratio, are correlated negatively with nutritional quality, while CP, IVDMD, and ash contents correlate with it positively [14]. Although the external validation did not indicate high performance of the calibrations for ADF and ash contents, we included them in the statistical analyses and discussion, since they fitted well the abovementioned general patterns, and their inclusion or exclusion did not change the general results. The steady tannins values (Table 6), confirm that gazelles browse all year round [5,6]. However, relatively low values of tannins suggest that browsing is not the main component in the gazelle diet. In comparison, the diet of goats contains $5 \%$ of tannins throughout most of the year [58]. Relatively high levels of digestibility, ash, and low levels of ADF and NDF in winter indicate the importance of lush green grass during this season [5,14], while autumn is the most challenging season, as shown by the highest NDF and ADF contents, along with low digestibility and CP contents, following vegetation senescence and weathering. Another index for the low nutritional value of food in autumn is the peak in C:N ratio. Between the two extremes of the propitious winter and the challenging autumn that are associated with significant differences in rumen estimates of food quality, spring and summer present intermediate values.

While seasonality plays a major role in the dynamics of nutrition, ecosystem type and, to a lesser extent, sex and age-class also affect gazelle nutrition. Although not always statistically significant, it appears that gazelles in dry ecosystems consume a diet of lower quality compared to more temperate zones, which may be correlated with lower productivity in these ecosystems. Alas, the relatively small sample size of gazelles from dry ecosystems in our database hindered more elaborate and robust inference on the effect of this factor on gazelle nutrition. It should also be noted that the lesser CP supply, the higher urea recycling [61], which might dampen the reflectance in rumen $\mathrm{CP}$ of seasonal and / or regional changes in $\mathrm{CP}$, i.e., $\mathrm{CP}$ changes in nutrition may be greater than changes in rumen contents.

Protein content is similar for male and female gazelle. This result is somewhat surprising, as females, which, on average weigh $30 \%$ less than males [65] are expected to have higher nutritional demands, in general, due to lower body weight [66], and specifically during gestation and lactation [7], while the nutrition of males typically degrades during the mating season [67], when they fight other males for territories, and pursue females. 
One possible explanation is that gazelles reproduce year-round in large parts of the country's Mediterranean region, although with a peak in births during spring $[1,6,67]$, and it might be that, overall, differences between sexes balance out on a yearly scale. Perhaps a reproductive seasonality would have yielded seasonal patterns, exhibiting better nutrition consumed by fighting males during the mating season and by females during periods of birth and lactation, approximately six months later [65]. This may be the case with the Dorcas gazelle (G. dorcas), which resides in more arid ecosystems in the area, and has strong reproduction seasonality [68]. It is interesting to note that, although statistically significant only for ash and C:N ratio, all constituents excluding tannins values (PEG-b-t), indicate that adult gazelles consume a somewhat better diet than young ones, which might suggest that food selection is a skill that improves with age and experience [69].

By and large, seasonal fluctuations are very apparent in rumen attributes, but the amplitude of fluctuation is relatively low: it represents a change between winter and autumn of approximately $30 \%$ in ruminal CP, IVDMD, and ash, and of $14-22 \%$ in ADF, $\mathrm{NDF}$, and C:N ratio. For comparison, dietary $\mathrm{CP}$ is threefold higher in winter than in summer in cattle grazing on herbaceous rangelands, where gazelles thrive $[14,16]$. It is noteworthy that the rainfall during the research period was relatively high. In 2018, 2019, 2020 the Mediterranean region in Israel received approximately $120 \%, 130 \%$, and $100 \%$ of the average annual rainfall, respectively, while drier parts of G. gazella range received $100 \%, 129 \%$, and $69 \%$, respectively [70]. Another possible explanation to the relatively steady nutrition, may be the access that gazelles in many areas throughout the country have to irrigated crops. It might be that under harsher conditions, i.e., years with less rain, or without access to cultivated crops, nutrition in summer and autumn will deteriorate, but it seems that gazelles, as goats [58,59], do not aim at selecting the best diet possible when food items and their nutritional quality change, but instead choose a diet which will be relatively constant, with small fluctuations. This tendency might have to do with the ruminal microbiome, which performs optimally when a relatively steady state is kept [49]. Overall, it seems that, in any situation, gazelle nutrition did not deteriorate to such low levels that it could be regarded as nutritional deficiency, which suggests that nutrition is not a major factor in gazelle survival. This notion complies with a study on the drivers of G. arabica dynamics in an arid setting, which found that the main driver of the population size was predation, while food availability had no significant effect [11]. One management implication of this conclusion is that should attempts to support gazelle populations be considered, they should focus on aspects other than nutrition, mainly predation.

\section{Conclusions}

Roadkills can serve as an important source of samples to study the nutrition of endangered species, specifically, when combined with NIRS. Hence such sad events can be used to direct and enhance conservation efforts.

Furthermore, NIRS prediction equations for constituents in rumen contents can be attained using existing databases of feeds, i.e., natural and cultivated plants.

Season plays a major role in gazelle nutrition, while ecosystem type and age class slightly affect nutrition, but the changes by each factor are mild. Gazelles' nutrition is best in winter and worst in autumn, with intermediate levels in spring and summer. Gazelle nutrition in Mediterranean ecosystems is slightly better than in dry ones, and for adults than young gazelles. However, gazelle nutrition does not drop drastically in any circumstances, which might suggest that nutrition is not a major driver of gazelle demography. The results of this study can serve as a benchmark for future studies on the nutritional status of local gazelle populations. 
Author Contributions: Conceptualization, A.A., S.Y.L. and G.D.; Data curation, A.A., Y.L.-P. and T.D.-T.; Formal analysis, A.A., S.Y.L., T.D.-T. and H.V.; Funding acquisition, A.A. and G.D.; Methodology, A.A., S.Y.L., T.D.-T., H.V. and G.D.; Software, S.Y.L. and T.D.-T.; Supervision, S.Y.L., I.I. and D.M.; Validation, A.A., S.Y.L. and T.D.-T.; Visualization, A.A. and O.S.; Writing-original draft, A.A. and S.Y.L.; Writing-review and editing, A.A., S.Y.L., I.I, D.M., H.V. and G.D. All authors have read and agreed to the published version of the manuscript.

Funding: This research was funded by Ramat Hanadiv.

Acknowledgments: We are indebted to the staff of the Wildlife Hospital and, in particular to Roni Elias and Afrine Bonstein; to Roni King, NPA rangers and ecologists; to the staff of National Zoological Collections at the Steinhardt Museum of Natural History, in particular, to Amos Belmaker, Erez Maza, Igor Gavrilov, and Karin Tamar, and to Hussein Muklada, Merav and Eran Yuval, Tamir Ben Mayor and Ofer Brill.

Conflicts of Interest: The authors declare no conflict of interest.

\section{References}

1. Yom-Tov, Y. The Gazelles of Israel; Dan Pery: Jerusalem, Israel, 2016. (In Hebrew)

2. IUCN SSC ANTELOPE SPECIALIST GROUP. Gazella gazella. In The IUCN Red List of Threatened Species. 2017. Available online: https: / / doi.org/10.2305/IUCN.UK.2017-2.RLTS.T8989A50186574.en (accessed on 1 June 2021).

3. Yom-Tov, Y.; Balaban, A.; Hadad, E.; Weil, G.; Roll, U. The plight of the Endangered mountain gazelle Gazella gazella. Oryx 2020, 55, 1-8. [CrossRef]

4. Hadas, L.; Hermon, D.; Boldo, A.; Arieli, G.; Gafny, R.; King, R.; Bar-Gal, G.K. Wild Gazelles of the Southern Levant: Genetic Profiling Defines New Conservation Priorities. PLoS ONE 2015, 10, e0116401. [CrossRef]

5. Baharav, D. Food habits of the mountain gazelle in semi-arid habitats of eastern Lower Galilee, Israel. J. Arid Environ. 1981, 4, 63-69. [CrossRef]

6. Baharav, D. Observation on the ecology of the mountain gazelle in the Upper Galilee, Israel. Mammalia 1983, 47, 59-70. [CrossRef]

7. Parker, K.L.; Barboza, P.S.; Gillingham, M.P. Nutrition integrates environmental responses of ungulates. Funct. Ecol. 2009, 23, 57-69. [CrossRef]

8. Prins, H.H.T.; Langevelde, F. Van Resource Ecology; Prins, H.H.T., Van Langevelde, F., Eds.; Springer: Dordrecht, The Netherlands, 2008; ISBN 978-1-4020-6848-5.

9. Spitzer, R.; Felton, A.; Landman, M.; Singh, N.J.; Widemo, F.; Cromsigt, J.P.G.M. Fifty years of European ungulate dietary studies: A synthesis. Oikos 2020, 129, 1668-1680. [CrossRef]

10. Landau, S.Y.; Isler, I.; Dvash, L.; Shalmon, B.; Arnon, A.; Saltz, D. Estimating the Suitability for the Reintroduced Arabian Oryx (Oryx leucoryx, Pallas 1777) of Two Desert Environments by NIRS-Aided Fecal Chemistry. Remote Sens. 2021, 13, 1876. [CrossRef]

11. Shalmon, B.; Sun, P.; Wronski, T. Factors Driving Arabian Gazelles (Gazella arabica) in Israel to Extinction: Time Series Analysis of Population Size and Juvenile Survival in an Unexploited Population. Biodivers. Conserv. 2020, 29, 315-332. [CrossRef]

12. Hodgman, T.P.; Davitt, B.B.; Nelson, J.R. Monitoring Mule Deer Diet Quality and Intake with Fecal Indices. J. Range Manag. 1996, 49, 215. [CrossRef]

13. Macandza, V.; Owen-Smith, N.; Le Roux, E. Faecal nutritional indicators in relation to the comparative population performance of sable antelope and other grazers. Afr. J. Ecol. 2013, 52, 300-307. [CrossRef]

14. Landau, S.Y.; Dvash, L.; Yehuda, Y.; Muklada, H.; Peleg, G.; Henkin, Z.; Voet, H.; Ungar, E.D. Impact of animal density on cattle nutrition in dry Mediterranean rangelands: A faecal near-IR spectroscopy-aided study. Animal 2018, 12, 265-274. [CrossRef]

15. Moore, J.; Goetsch, A.; Luo, J.; Owens, F.; Galyean, M.; Johnson, Z.; Sahlu, T.; Ferrell, C. Prediction of fecal crude protein excretion of goats. Small Rumin. Res. 2004, 53, 275-292. [CrossRef]

16. Landau, S.Y.; Dvash, L.; Roudman, M.; Muklada, H.; Barkai, D.; Yehuda, Y.; Ungar, E.D. Faecal near-IR spectroscopy to determine the nutritional value of diets consumed by beef cattle in east Mediterranean rangelands. Animal 2016, 10, 192-202. [CrossRef]

17. Hudson, R.J.; White, R.G. Bioenergetics of Wild Herbivores; Hudson, R.J., White, R.G., Eds.; CRC Press: Boca Raton, FL, USA, 1985.

18. Holechek, J.L.; Vavra, M.; Arthun, D. Relationships between performance, intake, diet nutritive quality and fecal nutritive quality of cattle on mountain range. J. Range Manag. 1982, 35, 741-744. [CrossRef]

19. Van Soest, P.J.; Robertson, J.B.; Lewis, B.A. Methods for Dietary Fiber, Neutral Detergent Fiber, and Nonstarch Polysaccharides in Relation to Animal Nutrition. J. Dairy Sci. 1991, 74, 3583-3597. [CrossRef]

20. White, T.C.R. The Inadequate Environment; Springer: Berlin/Heidelberg, Germany, 1993; ISBN 978-3-642-78301-2.

21. Leslie, D.M.; Bowyer, R.T.; Jenks, J.A. Facts from Feces: Nitrogen Still Measures up as a Nutritional Index for Mammalian Herbivores. J. Wildl. Manag. 2008, 72, 1420-1433. [CrossRef]

22. Djordjevic, N.; Popovic, Z.; Grubic, G. Chemical composition of the rumen contents in roe deer (Capreolus capreolus) as potential quality indicator of their feeding. J. Agric. Sci. Belgrade 2006, 51, 133-140. [CrossRef]

23. König, A.; Hudler, M.; Dahl, S.A.; Bolduan, C.; Brugger, D.; Windisch, W. Response of roe deer (Capreolus capreolus) to seasonal and local changes in dietary energy content and quality. Anim. Prod. Sci. 2020, 60, 1315-1325. [CrossRef] 
24. Ballari, S.A.; Barrios-García, M.N. A review of wild boar Sus scrofa diet and factors affecting food selection in native and introduced ranges. Mamm. Rev. 2014, 44, 124-134. [CrossRef]

25. Dixon, R.; Coates, D. Review: Near Infrared Spectroscopy of Faeces to Evaluate the Nutrition and Physiology of Herbivores. J. Near Infrared Spectrosc. 2009, 17, 1-31. [CrossRef]

26. Lancaster, R.J. The measurement of feed intake by grazing cattle and sheep. I. A method of calculating the digestibility of pasture based on the nitrogen content of feces derived from the pasture. N. Z. J. Sci. Technol. 1949, 31, 31-38.

27. Jean, P.-O.; Bradley, R.L.; Giroux, M.-A.; Tremblay, J.-P.; Côté, S.D. Near Infrared Spectroscopy and Fecal Chemistry as Predictors of the Diet Composition of White-Tailed Deer. Rangel. Ecol. Manag. 2014, 67, 154-159. [CrossRef]

28. Jianzhang, M.; Junsheng, L.; Zhaowen, J.; Mingbo, G. Nitrogen and fiber concentration in rumen contents and feces contents of Mongolian gazelles. J. For. Res. 1999, 10, 103-106. [CrossRef]

29. Blanchard, P.; Festa-Bianchet, M.; Gaillard, J.-M.; Jorgenson, J.T. A Test of Long-Term Fecal Nitrogen Monitoring to Evaluate Nutritional Status in Bighorn Sheep. J. Wildl. Manag. 2003, 67, 477. [CrossRef]

30. Irwin, L.L.; Cook, J.G.; McWhirter, D.E.; Smith, S.G.; Arnett, E.B. Assessing Winter Dietary Quality in Bighorn Sheep via Fecal Nitrogen. J. Wildl. Manag. 1993, 57, 413. [CrossRef]

31. Wang, C.J.; Tas, B.M.; Glindemann, T.; Rave, G.; Schmidt, L.; Weißbach, F.; Susenbeth, A. Fecal crude protein content as an estimate for the digestibility of forage in grazing sheep. Anim. Feed Sci. Technol. 2009, 149, 199-208. [CrossRef]

32. Peripolli, V.; Prates, Ê.R.; Barcellos, J.O.J.; Neto, J.B. Fecal nitrogen to estimate intake and digestibility in grazing ruminants. Anim. Feed Sci. Technol. 2011, 163, 170-176. [CrossRef]

33. Wehausen, J.D. Fecal Measures of Diet Quality in Wild and Domestic Ruminants. J. Wildl. Manag. 1995, 59, 816. [CrossRef]

34. Choshniak, I.; Arnon, H. Nitrogen metabolism and kidney function in the nubian ibex (Capra ibex nubiana). Comp. Biochem. Physiol. Part A Physiol. 1985, 82, 137-139. [CrossRef]

35. Barboza, P.S.; Bowyer, R.T. Sexual Segregetaion in Dimorphic Deer: A New Gastrocentric Hypothsis. J. Mammal. 2000, 81, 473-489. [CrossRef]

36. Klein, D.R.; Schønheyder, F. Variation in ruminal nitrogen levels among some cervidae. Can. J. Zool. 1970, 48, 1437-1442. [CrossRef]

37. Segelquist, C.A.; Short, H.L.; Ward, F.D.; Leonard, R.G. Quality of Some Winter Deer Forages in the Arkansas Ozarks. J. Wildl. Manag. 1972, 36, 174. [CrossRef]

38. Staines, B.W.; Crisp, J.M.; Parish, T. Differences in the Quality of Food Eaten by Red Deer (Cervus elaphus) Stags and Hinds in Winter. J. Appl. Ecol. 1982, 19, 65. [CrossRef]

39. Redjadj, C.; Darmon, G.; Maillard, D.; Chevrier, T.; Bastianelli, D.; Verheyden, H.; Loison, A.; Saïd, S. Intra- and Interspecific Differences in Diet Quality and Composition in a Large Herbivore Community. PLoS ONE 2014, 9, e84756. [CrossRef]

40. Spalton, J.A. The food supply of Arabian oryx (Oryx leucoryx) in the desert of Oman. J. Zool. 1999, 248, 433-441. [CrossRef]

41. Cen, H.; He, Y. Theory and application of near infrared reflectance spectroscopy in determination of food quality. Trends Food Sci. Technol. 2007, 18, 72-83. [CrossRef]

42. Shenk, J.S.; Westerhaus, M.O. Near Infrared Reflectance Analysis with Single and Multiproduct Calibrations. Crop Sci. 1993, 33, 582-584. [CrossRef]

43. Mark, H.; Ritchie, G.E.; Roller, R.W.; Ciurczak, E.W.; Tso, C.; MacDonald, S.A. Validation of a near-infrared transmission spectroscopic procedure, part A: Validation protocols. J. Pharm. Biomed. Anal. 2002, 28, 251-260. [CrossRef]

44. Landau, S.; Glasser, T.; Dvash, L.; Perevolotsky, A. Faecal NIRS to monitor the diet of Mediterranean goats. S. Afr. J. Anim. Sci. 2004, 34, 76-80.

45. Purnomoadi, A.; Kurihara, M.; Nishida, T.; Terada, F.; Abe, A. Prediction of Feed Digestibility Using Differences in NIRS Spectra between Feeds and Feces at a Determined Region of Wavelength. Nihon Chikusan Gakkaiho 1998, 69, 253-259. [CrossRef]

46. AOAC. Official Methods of Analysis; Association of Official Analytical Chemist: Arlington, VA, USA, 1990.

47. Goering, H.K.; Van Soest, P.J. Forage Fiber Analyses, Apparatus, Reagents, Procedures, and Some Applications; ARS-USDA: Washington, DC, USA, 1970.

48. Tilley, J.M.A.; Terry, R.A. A Two-Stage Technique for the In Vitro Digestion of Forage Crops. Grass Forage Sci. 1963, 18, $104-111$. [CrossRef]

49. Van Soest, P.J. Nutritional Ecology of the Ruminant; O \& B Books: Corvallis, OR, USA, 1982.

50. Nocek, J.E. In situ and Other Methods to Estimate Ruminal Protein and Energy Digestibility: A Review. J. Dairy Sci. 1988, 71, 2051-2069. [CrossRef]

51. Barnes, R.J.; Dhanoa, M.S.; Lister, S.J. Standard Normal Variate Transformation and De-Trending of Near-Infrared Diffuse Reflectance Spectra. Appl. Spectrosc. 1989, 43, 772-777. [CrossRef]

52. ISI. WinISI, the Complete Software Solution for Routine Analysis, Robust Calibrations and Networking; Infrasoft International LLC: State College, PA, USA, 1999.

53. Glasser, T.; Landau, S.; Ungar, E.D.; Perevolotsky, A.; Dvash, L.; Muklada, H.; Kababya, D.; Walker, J.W. A fecal near-infrared reflectance spectroscopy-aided methodology to determine goat dietary composition in a Mediterranean shrubland. J. Anim. Sci. 2004, 86, 1345-1356. [CrossRef]

54. Shenk, J.S.; Westerhaus, M.O. Population Definition, Sample Selection, and Calibration Procedures for Near Infrared Reflectance Spectroscopy. Crop Sci. 1991, 31, 469-474. [CrossRef] 
55. Martens, H.; Naes, T. Multivariate calibration by data comparison. In Near-Infrared Technology in the Agricultural and Food Industry; Williams, P.C., Norris, K., Eds.; American Association of Cereal Chemists: St. Paul, MN, USA, 1987.

56. Naes, T.; Isakson, T.; Fearn, T.; Davies, T. Validation. In A User-Friendly Guide to Multivariate Calibration and Classification; Naes, T., Isakson, T., Fearen, T., Davies, T., Eds.; NIR Publications: Chichester, UK, 2002; pp. 155-177.

57. Williams, P.; Sobering, D.C. Near Infrared Spectroscopy: The Future Waves; Davies, A.M.C., Williams, P.C., Eds.; NIR Publications: Chichester, UK, 1995; pp. 6-11.

58. Glasser, T.A.; Landau, S.Y.; Ungar, E.D.; Perevolotsky, A.; Dvash, L.; Muklada, H.; Kababya, D.; Walker, J.W. Foraging selectivity of three goat breeds in a Mediterranean shrubland. Small Rumin. Res. 2012, 102, 7-12. [CrossRef]

59. Kababya, D.; Perevolotsky, A.; Bruckental, I.; Landau, S.Y. Selection of diets by dual-purpose Mamber goats in Mediterranean woodland. J. Agric. Sci. 1998, 131, 221-228. [CrossRef]

60. Maloiy, G.M.O.; Rugangazi, B.M.; Clemens, E.T. Nitrogen metabolism and renal function in the dik-dik antelope (Rhynchotragus kirkii). Small Rumin. Res. 2000, 37, 243-248. [CrossRef]

61. Silanikove, N.; Tagari, H.; Shkolnik, A. Gross energy digestion and urea recycling in the desert black Bedouin goat. Comp. Biochem. Physiol. Part A Physiol. 1980, 67, 215-218. [CrossRef]

62. Schwartz, A.L.W.; Shilling, F.M.; Perkins, S.E. The value of monitoring wildlife roadkill. Eur. J. Wildl. Res. 2020, 66, 18. [CrossRef]

63. Krumm, C.E.; Conner, M.M.; Miller, M.W. Relative Vulnerability of Chronic Wasting Disease Infected Mule Deer to Vehicle Collisions. J. Wildl. Dis. 2005, 41, 503-511. [CrossRef] [PubMed]

64. Lo, J.R.; Colom-cadena, A.; Marco, I.; Ramanzin, M.; Ferna, X.; Albanell, E. Predicting herbivore faecal nitrogen using a multispecies near-infrared reflectance spectroscopy calibration. PLoS One 2017, 12, e0176635.

65. Mendelsshon, H.; Yom-Tov, Y.; Groves, C. Gazella gazella. Mamm. Species 1995, 490, 1-7.

66. Demment, M.; Van Soest, P.J. A Nutritional Explanation for Body-Size Patterns of Ruminant and Nonruminant Herbivores. Am. Nat. 1985, 125, 641-672. [CrossRef]

67. Mysterud, A.; Langvatn, R.; Stenseth, N.C. Patterns of reproductive effort in male ungulates. J. Zool. 2004, 264, 209-215. [CrossRef]

68. Baharav, D. Reproductive strategies in female Mountain and Dorcas gazelles (Gazella gazella gazella and Gazella dorcas). J. Zool. 1983, 200, 445-453. [CrossRef]

69. Landau, S.Y.; Provenza, F.D. Of browse, goats, and men: Contribution to the debate on animal traditions and cultures. Appl. Anim. Behav. Sci. 2020, 232, 105127. [CrossRef]

70. Israel Meteorological Service. Available online: https://ims.gov.il/en (accessed on 1 June 2021). 